\section{METEOROLOGY IN AMERICA *}

\section{III.-SELF-REGISTERING INSTRUMENTS}

INALUABLE as is the ordinary barometer, the most valuable instruments are those which are automatic, or self-registering. Prominent among those used in America are the Self-recording Barometer and Meteorograph invented by Prof. G. W. Hough, Superintendent of the Dudley Observatory. Lord Rosse's telescope has not done more for astronomy than will the self-registering barometer do for meteorology.

The diagram, Fig. 7, will illustrate the method of registering the height of the barometer and thermometer on a single sheet, by the use of one set of mechanism in these simple yet complete and consummate contrivances.

Let $\mathrm{D}$ be a drum six inches in diameter and seven inches in height, covered with a sheet of ruled paper. This drum is presumed to revolve at any convenient rate, say one inch per day. Let $L$ be an iron or brass bar twenty-four inches in length, mounted on an axis passing through the point $c$. Let $\mathrm{P}$ be a steel pen attached to the end of the lever projecting over the centre of the drum. Let $\mathrm{P}^{\prime}$ and $\mathrm{P}^{\prime \prime}$ be platinum wires attached to the lever at three inches on either side of the axis $c$. The wire $\mathrm{P}^{\prime}$ is over the shorter leg of a siphon barometer, and the wire $\mathrm{P}^{\prime \prime}$ passes into the end of an open mercury thermometer. Now if the lever $L$ be elevated at the end over the drum, the wire $\mathrm{P}^{\prime}$ will touch the top of a float resting in the shorter leg of the siphon barometer If then a battery, $\mathrm{B}$, and electro-magnet, $\mathrm{E}$, be arranged as in the diagram, when contact is made with the float, a current of electricity will pass through the circuit, and the electro-magnet $\mathrm{E}$ is operated. If then, when the circuit is completed, $\mathrm{a}$

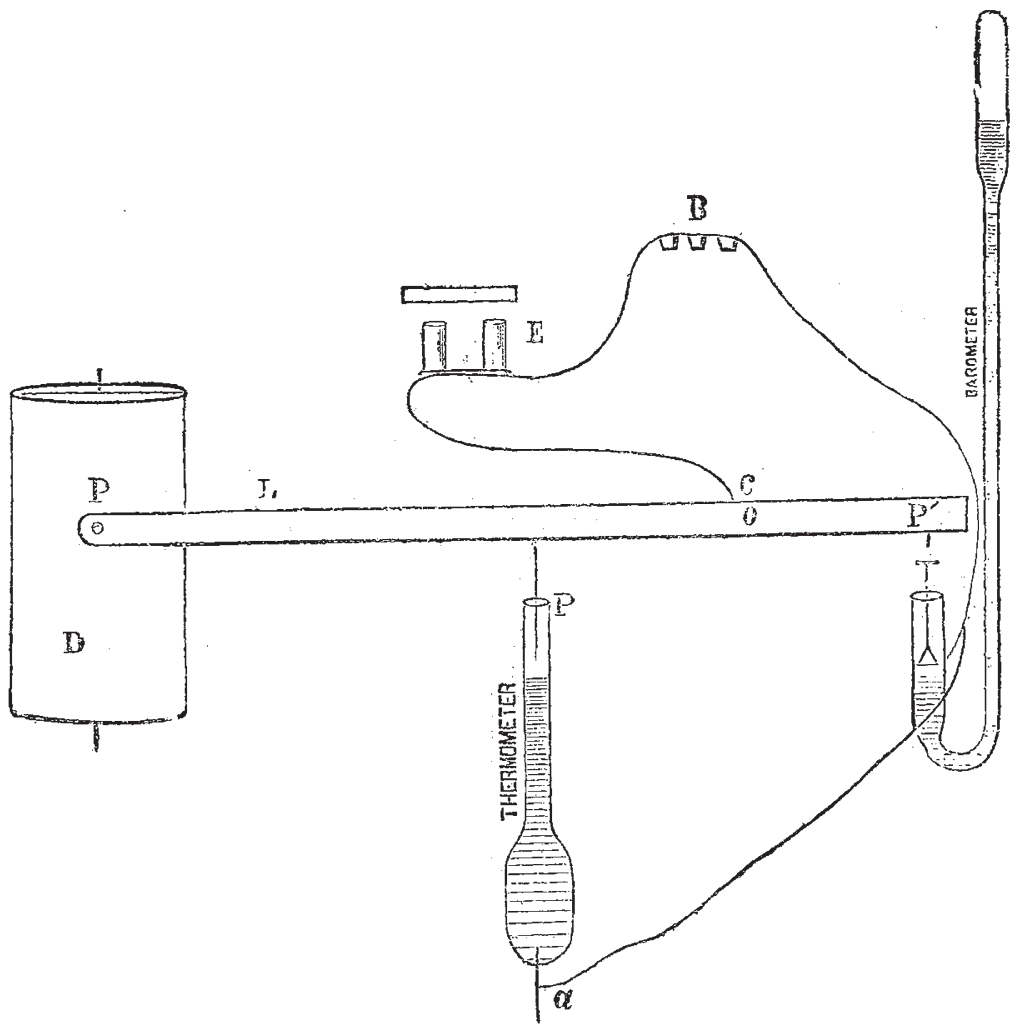

PIG. 7- REGISTRATION OF THE HEIGHT OF BAROMETER AND THERMOMETER

blow be struck on the pen $P$, by means of the electromagnet, or a hammer unlocked by it, the dot on the drum sheet will indicate the height of the barometer at that time. It is obvious that as often as the lever is elevated a record will be made. For the barometer an hourly record will be found to be sufficient.

If the lever $L$ is rigid and firmly mounted, the mere measurement of height by means of electrical contact can be carried to almost any degree of precision.

It was found from numerous experiments made some years since, that the magnetic circuit is not completed for a distance of one ten-thousandth of an inch. Therefore, whatever source of error there may be in the results recorded by this method is due to the barometer itself. In * We are again indebted to Harper's New Monthly Magazine for the
continuation of the article by Prof. Maury, and the woodcuts which we reproduce this week. practice, from records extending over nearly one year, it is found that the results are inside the errors of reading from the drum sheet.

A long experience has led to the conclusion that this degree of precision is sufficient for the investigation of barometric changes, and is but little outside the limit of error from reading a standard barometer.

An examination of the diagram will also show at a glance how the height of the thermometer is recorded. It should, however, previously be stated that the thermo. meter is a little larger than those in ordinary use, and has a platinum wire, $a$, cemented in the bulb, communicating with the mercury in the inside.

The following is a general description of a machine constructed for the Signal Service at the request of the chief signal officer.

It registers hourly the barometer and wet and dry bulb 
thermometers, and thus shows the atmospheric pressure, the temperature of the atmosphere, and its hygrometric condition-i.e., its condition of moisture or dryness.

The engraving, Fig. 8, is a perspective view of this instrument. The recording lever, $A$, is a bar of iron about two feet in length, nearly balanced on the axis, supported by the clock-frame, C. The clock is constructed with rather stronger gearing than an ordinary movement, its office being to elevate and depress the lever A hourly, regulate the drum, $\mathrm{D}$, and raise the two striking hammers, $\mathrm{H}$ and $\mathrm{H}^{\prime}$. It is provided with a half-second pendulum, and requires winding once in two days, the weight dropping in that time about three feet.

The shorter leg of the siphon barometer is shown at B, and the wet and dry bulb thermometers at $\mathrm{T}^{\prime}$ and $\mathrm{T}$. Directly over the leg of the siphon, as also over the two

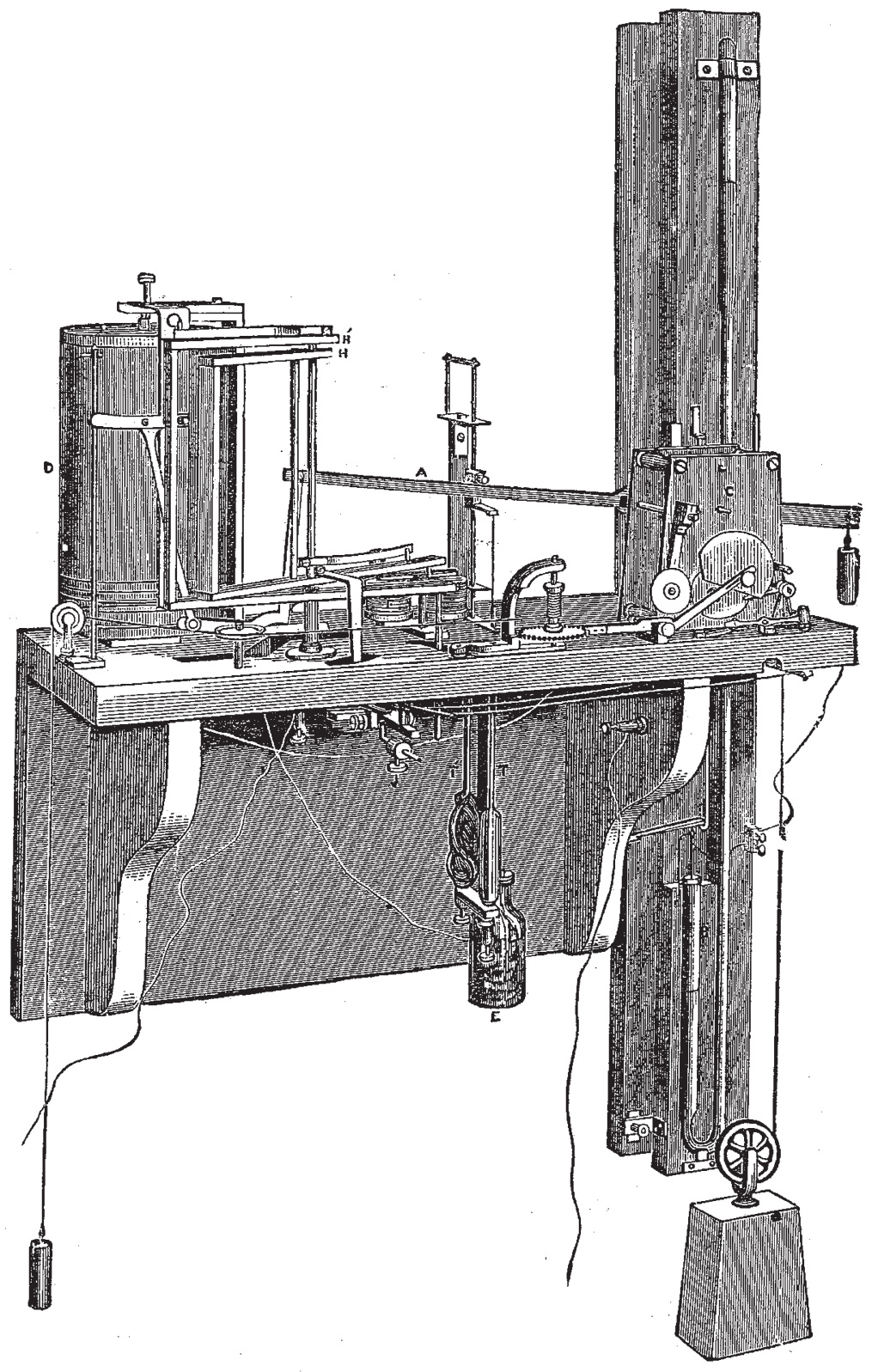

FIG. 8, -THE METEOROGRAPH

thermometers, the lever A supports a carriage, which is depressed or elevated whenever the lever A is in motion. The registering point, $G$, is connected with the lever, as shown in the diagram; and the curvilinear motion of the end of the lever is converted into rectilinear by allowing $G$ to slide against a vertical steel rod.

To illustrate the action of the machine, we will suppose the lever $\mathrm{A}$ has reached its lowest point, the registering pen $\mathrm{G}$ being at the lottom of the drum. Now, in order that we may be able to register the barometer on any part of the drum sheet, it is necessary that the striking hammer should be elevated and locked before the upward motion of the lever cornmences. As the hammers are raised by means of an arm carried by the hour shaft of the clock, at the point where the hammers begin to rise the snail for elevating the lever $\mathrm{A}$ is cut away, so that it remains at 
rest during a period of fifteen minutes, the time required for elevating the hammers $\mathrm{H}$ and $\mathrm{H}^{\prime}$. As soon as this is accomplished, the lever begins to rise slowly by means of the double snail on the hour shaft, the time required for traversing the drum being about fifteen minutes. When the position of the lever is such that the carriage in the rear of the clock touches the float in the shorter leg of the siphon, an electric current is established through the magnet, $\mathrm{F}$, which unlocks the hammer $\mathrm{H}$, causing the pen $G$ to make a record on the drum sheet. After the lever has reached the top of the drum, it remains at rest fifteen minutes while the hammers are being raised, when it is gradually depressed. So soon as the platinum wiresattached to the carriage over the thermometers-touch the surface of the mercury in the thermometer tubes, electric currents are established through the magnets $F$ and J, simultaneously or successively unlocking the hammers, and, as the case may be, making records as before.

A complete double motion of the lever requires one hour. During this time the barometer and wet and dry bulb thermometers have each been recorded once. The records of the barometer and thermometers differ in time about half an hour. The wet and dry bulb thermometers are recorded within about one minute of each other, depending on the difference between them.

One of the most marked and wonderful features of the invention of Prof. Hough is that it prints its own records. And this is done by a single screw, which rises or falls
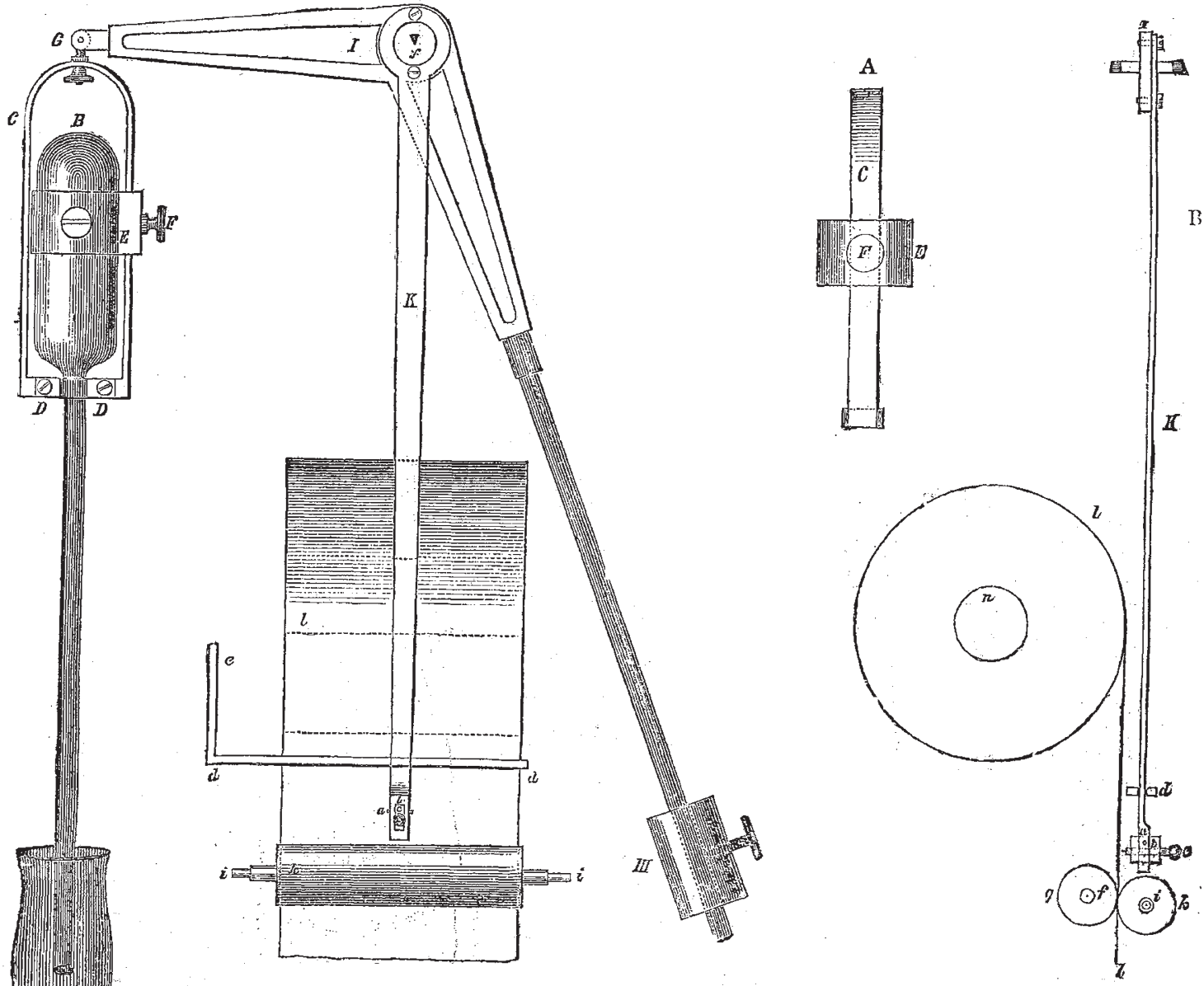

FIG. 9-WILD'S SELF-REGISTERING BAROMETER (BAROMETER TUBE MOVEABLE)

with the mercury in the barometer. This screw carries a pencil, which traces upon a revolving cylinder or roll of paper a line showing the minutest movements of the column of mercury for every minute in twenty-four hours. This same screw also gives motion to a series of wheels which carry types, by which, at the end of every hour, the height of the column of mercury is printed on a slip of paper to the accuracy of the thousanith part of an inch!

One of the most beautiful and simple contrivances used is a Wild's Self-registering Barometer, of which we give a: cut one quarter the actual size. It scarcely needs explanation, except to say that the tube $A$ is suspended in a cistern of mercury, represented on the left of Fig. 9. As the atmospheric pressure changes, the level of the mercury changes in the cistern, and the tube A rises or falls as the atmospheric pressure increases or diminishes. The weight of this tube as it floats in the mercury, and also that of the $\operatorname{arm} I$, which supports it at $G$, is exactly balanced by the arm $I I$, to which is attached a sliding weight, $I I I$, adjustable by a small thumb-screw. $K$ is a steel crayonholder fixed to the balance $I I I$, and to which is fixed a crayon, $c$, whose point in seen in $B$ to impinge upon a sheet of paper, $l l$. This sheet s moved by clock-work. When the atmospheric pressure is increased, the tube $A$ is forced to rise a little out of the mercury in which it 
floats, and as it rises at $G$, the $\operatorname{arm} I$ is elevated. The crayon holder, being fixed on the balance at the fulcrum, $f$, by two little screws, swings a little to the left, and the crayon which it carries with it makes a mark on the paper beneath it; which mark indicates the rise of the barometer, or the increase of atmospheric pressure. If the pressure decreases, the pencil, of course, moves in the opposite direction, and shows the barometric fall. The roll of paper on which the record is made by this automatic instrument is divided into rectangular parts, each one of which exhibits the atmospheric variations for twenty-four hours. At the end of every day this part of the roll is detached and put by to be bound up in book form in the records of the office in which the instrument is kept.
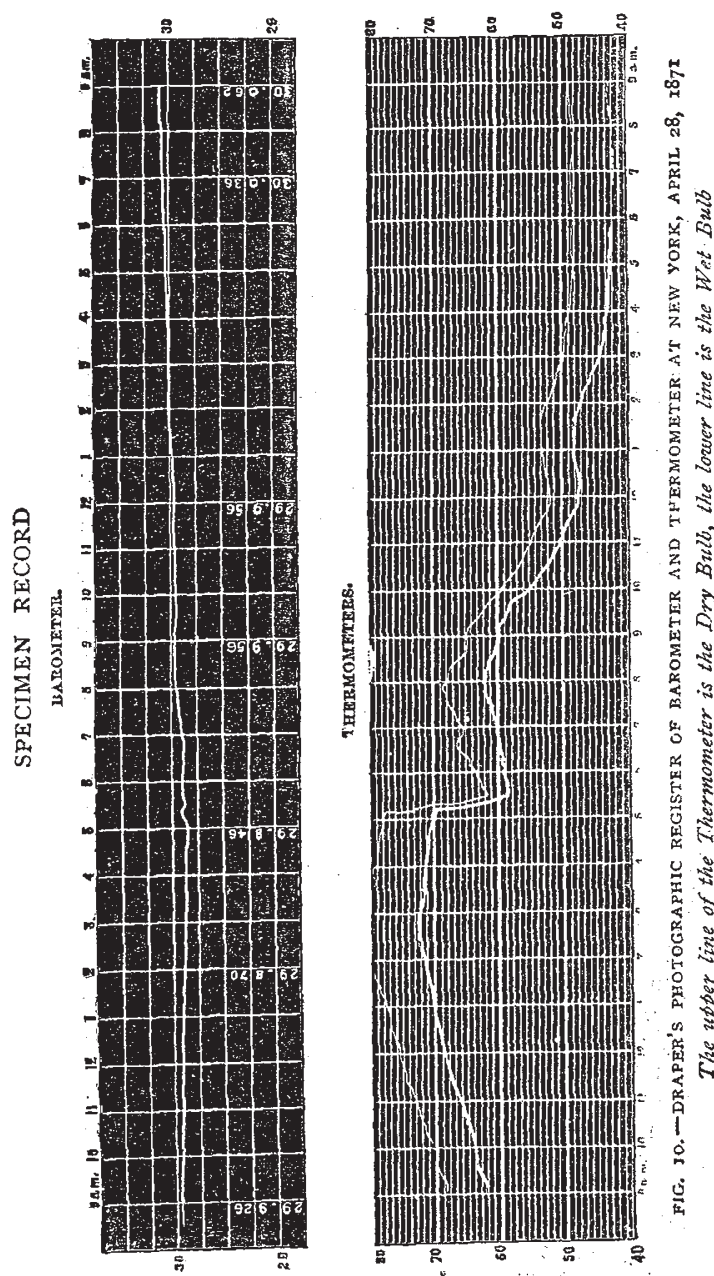

The roll of paper is on a reel, $n$, passing between two rollers, $g$ and $k$, as seen in $\mathrm{B}$ (Fig. 9).

By these perfectly simple devices, instead of obtaining only three daily recorded observations, the observer at every station gets a continuous and perpetual record for every second in the day. That is to say, instead of getting, as by the common barometer (observed three times a day), observations for three seconds in twenty-four hours, he gets them for as many seconds as there are in twenty-four hours, or 86,400 . Thus it follows that the value of the self-registering barometer, as compared with the ordinary one, is as 86,400 to 3 !

The marvellous accuracy and exquisite nicety with which all the observations forwarded to General Myer by the observers are marked ought to assure the public that nothing is wanting to give reliability to the published results and the "probabilities" issued from his officers. A self-registering barometer, as well as other instruments

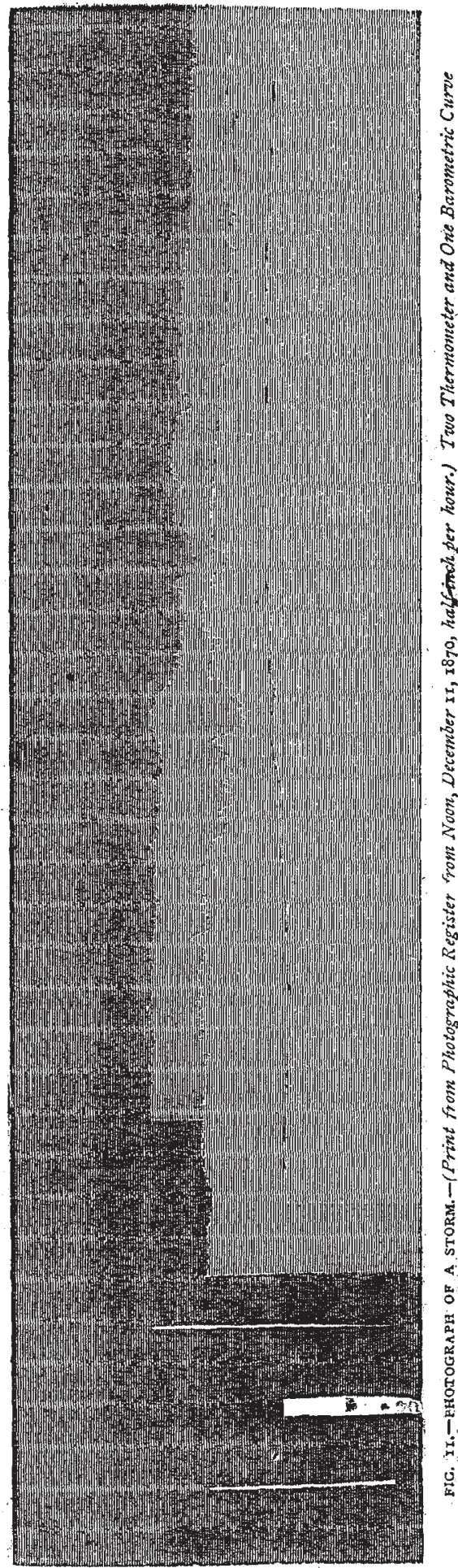

of equal sensitiveness, will be used by all the observersergeants. It is scarcely possible for this invaluable instrumert to suffer derangement or to get out of order.

A third most beautiful and sensitive self-registering 
instrument is that of Mr. Peelor, of Johnstown, Pennsylvania, used with great success and satisfaction by the Signal Service. This needs no battery, no electricity, to work it. A simple clock-work is all that is required, and its operations are as exquisitely accurate and trustworthy as the best navy chronometer.

A barograph and thermograph made by Mr. Beck, of London, similar to those used in the Kew Observatory, are on trial in the Signal Office, and good results are hoped from them. Their beautiful machinery might also be mentioned and described, but our space fails. Indeed, our limits have allowed mention to be made only of the most noyel instruments employed by the signal offices. A specimen record of one of these is presented in Fig. IO, showing the synchronous readings, on a given day and at a given place, of the thermometers (wet and dry bulb), the hygrometer, and the barometer, all upon one sheet of paper.

We have already spoken of the beautiful adaptation of Prof. Hough's Meteorograph to the work of printing its own registrations. The mechanics of meteorology have been advanced one step higher than this, and the registrations of the automaton are instantly and perfectly photographed. The sheet of paper, suitably prepared for photographic impressions, is made to slide, by means of clock-work, before a gas flame. The mercury in the tubes protects a portion of the paper from the action of the light of the lamp, while above the mercury the rays of the lamp fall unobstructed upon the paper, and, making their impression, reveal the exact height of the mercury in the tubes.

The "photograph of a storm," Fig. II, shows the movements of the mercury in the two thermometers and barometer for twelve hours.

This process, by which the weather is photographed, is employed by General Myer, and these necessarily exact records will prove most attractive pictorial representations of the great storms in the atmospheric ocean for the study of meteorologists all over the world.

\section{THE INTERNATIONAL EXHIBITION AT VIENNA FOR 1873}

$7 \mathrm{HE}$ Emperor of Austria has appointed an Imperial Commission to carry out the project of an International Exhibition to be held at Vienna in 1873 . The members of the Commission held their inaugural meeting in the hall of the Imperial Academy of Sciences at Vienna on Sunday, the 17 th of September, under the presidency of the Archduke Rainer.

The Exhibition is intended to be opened on the Ist of May, I873, under the especial patronage of the Emperor and his brother, the Archduke Charles Louis. The Commission, which is composed after the models of the English and French Commissions, consists of the Archduke Rainer, president ; the Lord Steward of the Imperial Household, Prince zu Hohenlohe-Schillingsfürst ; the Imperial Chancellor, Minister of the Imperial House and for Foreign Affairs, Count von Beust ; Prince zu Liechtenstein. Prince Schwarzenberg, Count Festetitz, and Count Potocki, vicepresidents; and the Lord High Chamberlain, Count Folliot de Crenneville, and other high courtiers, the Ministers and heads of departments, the Presidents of both Houses of the Reichsrath, the presidents of the chief artistic, commercial, and scientific societies, and a number of gentlemen who have distinguished themselves in the various branches of science, art, and industry.

The entire arrangements have been entrusted to the Austrian Consul-General at Paris, Privy Councillor Baron de Schwarz-Senborn, who has been nominated DirectorGeneral of the Exhibition. Local committees are about to be formed in the various provinces of Austria and Hungary, and a special Royal Commission is to be appointed at Pesth. The objects to be exhibited will be classified into 26 different groups, as detailed in the suboined programme.

One great feature of the Exhibition will be an arrangement for the classification of the productions of all countries in groups corresponding with their geographical position, and great pains will be taken to render the Oriental department in every way worthy of the almost inexhaustible resources of the Indian Empire. The position of Vienna is admirably adapted for this, having, besides the waters of the Danube, a direct communication with all the important harbours of the Levant vid Trieste. The arrangement of the Eastern department will be confided to the Austrian Consul at Constantinople, Dr. de Schwegel, who has already acquired a great reputation for his knowledge of Oriental habits and productions.

A new feature of the Exhibition will be an arrangement by which the treasured collections of the various museums of London, Paris, Berlin, Moscow, Lyons, Munich, Stuttgard, \&c., will appear in simultaneous position, and it is further intended to represent a history of inventions, a history of prices, a history of industry, and a history of natural productions, so that the world's progress in arts, science, industry, and natural products, will thus be brought into contrast. The Emperor of Austria has granted the use of the "Prater" for the site of the exhibition, and Mr. Scott Russell is at present in Vienna consulting with Baron von Schwarz as to the design for the building. Chevalier de Schaeffer, Director of the Austrian Consulate General in London, who gained great experience at the London and Paris Exhibitions, has been entrusted with the preliminary arrangements respecting the contributions to be sent to the Exhibition from Great Britain.

The objects to be exhibited will be classified in the following twenty-six groups :-I, Mining and Metallurgy; 2, Agriculture and Forestry ; 3, Chemical industry ; 4, Articles of food as industrial products ; 5 , Textile industry and clothing ; 6, Leather and india-rubber industry ; 7, Metal industry ; 8, Wood industry; 9, Stone, Earthenware, and Glass industry; IO, Hardware industry ; iI, Paper industry; 12, Graphical Arts and Industrial Drawing; 13 , Machinery and means of transport; 14 , Scientific instruments; I5, Nautical instruments; 16, Military accoutrements ; I7, Maritime objects ; I8, Architectural and Engineering objects; 19, Cottage houses, their interior arrangements and decorations; 20, Peasant houses, with their implements and arrangements; $2 \mathrm{I}$, National domestic industry; 22, Representation of the operation of Museums of Art and Industry; 23, Eccle. siastical Art ; 24, Objects of Art and Industry of former times, exhibited by amateurs and collectors ; 25, Plastic Art of the present time; 26, Objects of Education, Training, and Mental Cultivation.

Arrangements will be made for temporary exhibitions of such articles which by their nature do not admit of an exposition of long duration.

During the time the Exhibition is held, International Congresses are contemplated for the discussion of important questions to which either the Exhibition itself may give rise, or which may be specially suggested as themes suitable for international consideration.

The arrangement of the Exhibition will be geographical, that is to say, according to countries, but in such a manner that the different territories of production shall appear as nearly as possible in the same order as they are situated naturally in the direction from the west to the east.

\section{SCIENTIFIC USE OF THE MONT CENIS TUNNEL}

$A^{T}$ the sitting of the French Academy of Sciences on the 18 th inst., $M$. Elie de Beaumont read an elaborate paper on the scientific instruction which may be derived from a close examination of the collection which is to 